\title{
Association between social support and recovery from post-traumatic stress disorder after flood: a 13-14 year follow-up study in Hunan, China
}

Wenjie Dai ${ }^{1}$, Long Chen ${ }^{1,2}$, Hongzhuan Tan ${ }^{1}$, Jieru Wang ${ }^{1,3}$, Zhiwei Lai ${ }^{1}$, Atipatsa C. Kaminga ${ }^{1}$, Yan Li ${ }^{1}$ and Aizhong Liü ${ }^{1 *}$

\begin{abstract}
Background: Post-traumatic stress disorder (PTSD) is one of the most prevalent long-term psychiatric disorders among survivors of traumatic events. It is well established that social support has been related to the onset of PTSD after natural disasters. However, very little is known whether or not social support has had an influence on the recovery from the PTSD that was diagnosed after floods. This study, therefore, made a follow-up assessment of PTSD in flood victims 13-14 years after they were diagnosed with PTSD in 2000 to measure the prevalence rate of PTSD among them and identify the association between social support and their recovery from PTSD.

Methods: Victims who had experienced Dongting Lake flood in 1998 and had been diagnosed as having PTSD in 2000 were enrolled in this study. A follow-up survey was done between the years 2013 and 2014 to diagnose the victims again of PTSD using the DSM-IV criteria. Social support and its three dimensions were measured using the Chinese version of Social Support Rating Scale (SSRS), including objective support, subjective support and support utilization. Data were collected through face-to-face interviews using a structured questionnaire. Bivariate and multivariate logistic regression analyses were used to examine the relationship between social support and the recovery from PTSD after flood.

Results: Out of 321 subjects with prior PTSD, 51 (15.89\%) were diagnosed as still having PTSD. Logistic regression analyses indicated that the recovery from prior PTSD was significantly associated with social support (odds ratio $(\mathrm{OR})=0.202,95 \%$ confidence interval $(95 \% \mathrm{Cl})$ : 0.047-0.878), subjective support (OR $=0.236,95 \% \mathrm{Cl}: 0.080-0.694)$ and support utilization (OR $=0.245,95 \%$ Cl: $0.071-0.844)$.

Conclusions: The prevalence rate of current PTSD indicates that natural disasters, such as floods, may affect the mental health of victims for a long time. Social support was significantly associated with the recovery from prior PTSD, especially subjective support and support utilization.
\end{abstract}

Keywords: Post-traumatic stress disorder, Social support, Recovery, Flood

\footnotetext{
* Correspondence: lazroy@live.cn

${ }^{1}$ Department of Epidemiology and Health Statistics, School of Public Health,

Central South University, Hunan, China

Full list of author information is available at the end of the article
} 


\section{Background}

Flood is one of the most common and devastating natural disasters in the world. It may lead to direct economic loss, and may cause both physical and psychological injuries, particularly in developing countries with limited availability of coping mechanisms [1]. China has been seriously affected by floods. For example, a severe flood that struck the Yangzi River of China in 1998 affected over 180 million people. According to the New Report from Ministry of Health of China in 1999, the flood displaced 18.393 million people, destroyed 6.85 million houses, caused 4,150 deaths and yielded a direct economic loss of about $\$ 32$ billion. Dongting Lake, located south of the middle reach of the Yangzi River in Southern China, was one of the areas most affected by the floods. Hundreds of thousands of residents were homeless and many infrastructural and agricultural projects were also damaged, leaving survivors with some psychological problems, including posttraumatic stress disorder (PTSD).

PTSD is a complex and chronic disorder caused by unusual threats or catastrophic events. According to the latest edition of the Diagnostic and Statistical Manual (DSM-5), PTSD consists of four clusters of symptoms, namely intrusion, avoidance, negative alterations in cognition and mood, and hyper-arousal [2]. It has been estimated that the lifetime prevalence of PTSD in the general population is $1 \%$ to $9 \%$ [3]. Individuals with PTSD may experience a long recovery process after traumatic events [4]. For example, half of the police responders in the World Trade Center Health Registry with PTSD in 2003-2007 continued to have PTSD in 2011-2012 after the terrorist attack of September 11, 2001 [5]. In the past decades, researches on PTSD have mainly focused on PTSD after traumatic events like earthquakes [6-8], hurricanes [9-11], wars [12-15], and traffic accidents [16, 17]. Articles about PTSD after floods have been rarely reported [18-20], and none has reported the effect of social support on the recovery from PTSD.

Social support was reported to be an important moderator between stressors and psychological symptoms [21]. According to a recent meta-analysis investigating 25 potential risk factors of PTSD, social support was one of the most important risk factors [22]. Thus, this team of researchers conducted an epidemiological survey after Dongting Lake flood in 1998 between January and May 2000 , which revealed that the onset of PTSD was significantly associated with social support [23]. However, the impact of social support on the recovery from prior PTSD was still unknown. Therefore, this study was aimed at exploring the prevalence rate of current PTSD and examining the association between social support and the recovery from prior PTSD after the 1998 flood of Dongting Lake.

\section{Methods}

\section{Ethics statement}

This study was approved by the Ethics Committee of the Institute of Clinical Pharmacology, Central South University of China. Written informed consent was obtained from the participants.

\section{Participants}

Prior to this follow-up study, a cross-sectional study was conducted between January and May 2000, more than one year after Dongting Lake flood in 1998. It considered 8 counties (Datonghu, Yueyang, Qianlianghu, Lingxiang, Huarong, Ziyang, Anxiang and Longshan) by using a multi-stage stratified and cluster sampling method. These eight counties, located south of the middle reach of the Yangzi River in Southern China (a flood-prone area), were the catchment area of Dongting Lake and were directly exposed to the 1998 Dongting Lake flood. Victims of that disaster from these counties (aged 16 or above) formed the target population. A total of 25,478 subjects were interviewed and 2,336 of them were diagnosed as having PTSD according to the DSM-IV criteria, indicating that the incidence of PTSD was $9.2 \%$ [24].

This follow-up study, therefore, considered the group of victims diagnosed as having prior PTSD in the previous study as the target population. Victims with prior PTSD from Qianlianghu, Datonghu and Longshan were relocated and separated, thus the study area for this follow-up study was reduced to cover 5 counties, namely Yueyang, Lingxiang, Huarong, Ziyang and Anxiang. Those who suffered from mental retardation, dementia or other mental disorders (e g., schizophrenia, anxiety disorder) were excluded.

\section{Data collection}

Well qualified investigators were appointed to collect data. The minimum academic qualification of each investigator was a bachelor's degree in medicine. The investigators either had worked for the local Centers for Disease Control and Prevention or had studied in a medical school. All investigators went through the unified training which was guided by the written investigation manual before they started data collection. After the training, they went to the target population where they carried out face-to-face interviews with the participants using a structured questionnaire to obtain demographic information, flood-related stressors, post-flood stressors, social support, coping style and ascertain PTSD symptoms. Each investigator received onsite supervision from professional psychologists. Victims with prior PTSD in Huarong were interviewed in November, 2013; victims with prior PTSD in Ziyang and Anxiang were interviewed in June, 2014; victims with prior PTSD in Yueyang and Lingxiang were interviewed in September, 2014. 


\section{Measures}

\section{Social support}

The Chinese version of Social Support Rating Scale (SSRS) which was developed by Xiao Shuiyuan in 1994 was used to identify the social support status. The SSRS consists of 10 items and three dimensions, namely objective support, subjective support and support utilization. The dimension of objective support has 3 items: "I often live with my family members"; "I often get economic assistance from family members, relatives, friends, neighbors or others when faced with some economic difficulties"; "I often get consolation from family members, relatives, friends, neighbors or others when faced with some trouble." The dimension of subjective support contains 4 items: "I can turn to my friends for help when things go wrong"; "I often communicate with my neighbors"; "I often communicate with my colleagues"; and "my family will try their best to help me when things go wrong." The dimension of support utilization includes 3 items: "I often seek assistance proactively when I have some difficulties"; "I often communicate with others about my distress"; and "I often participate in societal activity." Each item is scored on a 4-point Likert scale ( 1 = none, 2 = slight, 3 = moderate, 4 = great). The total scores of all these ten items are used to assess the current social support status of individuals. Based on the established guideline [25], social support scores are defined as low $(\leq 44)$ and high $(>44)$; objective support scores are defined as low $(\leq 13)$ and high $(>13)$; subjective support scores are defined as low $(\leq 24)$ and high (>24); support utilization scores are defined as low $(\leq 9)$ and high $(>9)$. This tool was chosen because it had proved to have better reliability and validity [26]. For instance, the correlated coefficients between total scale and three subscales ranged from 0.724 to 0.835 , while Cronbach's alpha coefficients of total scale and subscales ranged from 0.825 to 0.896 [27].

\section{PTSD outcome}

In this study, the PTSD diagnosed at 13-14 years followup assessment is defined as "current PTSD" for clarity purposes. Thus, the outcome variable was current PTSD. The PTSD Checklist-Civilian version (PCL-C), which was used in the first study, was also used to identify current PTSD. The PCL-C is a commonly used self-reporting questionnaire for ascertaining PTSD. According to some relevant studies, the PCL-C is highly internally consistent $(\alpha=0.94)$ [28] and has relatively high levels of sensitivity (94-97\%) as well as specificity (86-99\%) [29].

The PCL-C consists of 17 items scored as $0=$ none, $1=$ slight, 2 =moderate, 3 = severe, and 4 =extreme. These 17 items are further divided into 3 groups, representing 3 clusters of symptoms, namely re-experiencing, avoidance and hyper-arousal. All the items referring to re-experiencing, half of the items referring to avoidance and half of the items referring to hyper-arousal contained event-specific wording (e.g., as a result of the Dongting Lake flood in 1998). Subjects with the score of not less than 2 are defined as positive for each item. The domain of re-experiencing includes 5 items and subjects are defined as positive if they score at least one positive item. The domain of avoidance included 7 items and subjects are defined as positive if they score at least three positive items. The domain of hyper-arousal includes 5 items and subjects are defined as positive if they score at least two positive items. After ascertaining PTSD using PCL-C, the diagnosis of current PTSD was made according to the DSM-IV criteria on subjects who scored positive under the three clusters of symptoms.

\section{Data analyses}

Simple descriptive statistics were computed for demographic data, flood-related stressors and post-flood stressors. Chi-square test was used to compare the demographic variables between the current PTSD group and the recovered from prior PTSD group. The same test was used to compare the relationship between current PTSD and social support. T-test was used to compare the distribution of social support score in different study groups, including age, gender, marital status, educational level, flood-related stressors, post-flood stressors. Bivariate logistic regression analyses were used to obtain crude OR for social support and its 3 categories, and multivariate logistic regression analyses were used to identify the independent role of social support after adjusting for age, gender, marital status, educational level, flood-related stressors, post-flood stressors and coping style. Each logistic regression model included only one social support variable to avoid multicollinearity among the different social support variables. All tests were 2-tailed and the significance level was set at 0.05 . All data were collected by Epidata 3.0 and all analyses were performed in SPSS Version 19.0 (IBM Corp, Armonk, NY).

\section{Results}

\section{Sample description}

A total of 1025 victims were diagnosed as having PTSD in Yueyang, Lingxiang, Huarong, Ziyang and Anxiang in 2000. Among these 1025 potential candidates, 86 died of diseases or accidents, 425 went to other cities to work and 168 migrated to other places. Finally 346 victims were available for this follow-up assessment of PTSD, representing $33.76 \%(346 / 1025)$ of the total group. Of the 346 interviewed subjects, 4 suffered from other mental diseases, 5 failed to communicate with interviewers because of serious illnesses and 16 had incomplete data. Accordingly, 321 subjects had complete data (Fig. 1), yielding a response rate of $95.25 \%$ (321/337). Compared with those excluded due to non-response or incomplete 


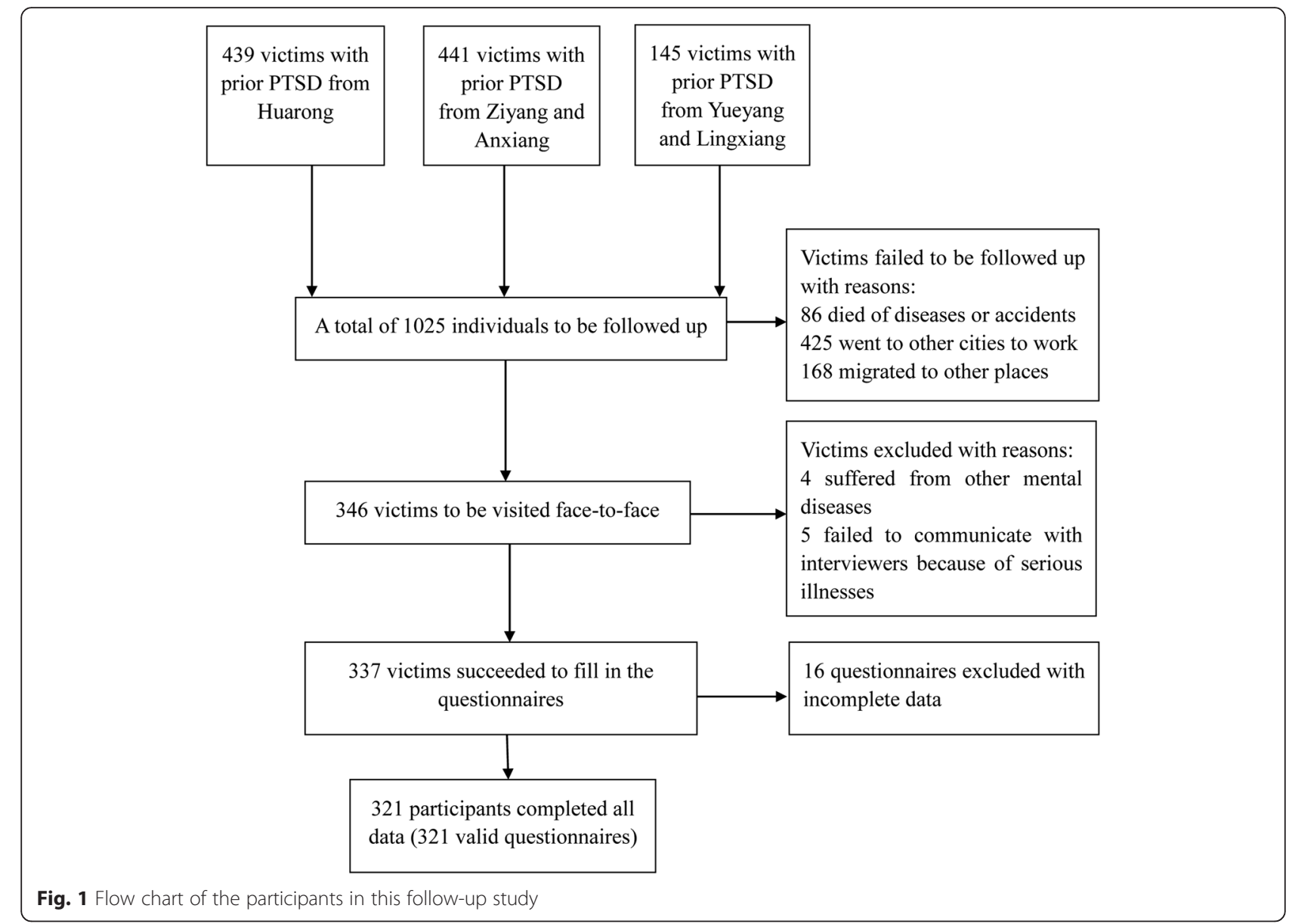

data, those included in this study were much older (median age on September 2014: 50.23 vs. 55.88 years, $P<0.05$ ), but they had similar trauma exposure.

Demographic characteristics of the 321 subjects are presented in Table 1. Majority (91.9\%) of the subjects were married and all were Han Nationality with a mean

Table 1 Basic characteristics of study participants

\begin{tabular}{llll}
\hline Variable & Values & Number & Percent (\%) \\
\hline Gender & & & \\
& Female & 148 & 46.1 \\
& Male & 173 & 53.9 \\
Age(year) & & & \\
& $29-59$ & 207 & 64.5 \\
& $\geq 60$ & 114 & 35.5 \\
Marital status & & & \\
& Married & 295 & 91.9 \\
& Unmarried & 26 & 8.1 \\
Educational level & & 172 & 53.6 \\
& sprimary school & 149 & 46.4 \\
\hline
\end{tabular}

(standard deviations) age of 55.88 (11.19) years. Nearly half $(46.1 \%)$ were female and also about half $(53.6 \%)$ of the subjects had not received any education or had only attended primary school.

Furthermore, 78 (24.3\%) had experienced at least 3 flood-related stressors and 61 (19.0 \%) had experienced at least 3 post-flood stressors after Dongting Lake flood in 1998. A total of 51 victims with prior PTSD were diagnosed as having current PTSD, yielding a prevalence rate of $15.89 \%$ (51/321) weighted by the composition of the overall target population. The composition of the overall target population is $75.7 \%$ and $24.3 \%$ for victims with not more than 2 flood-related stressors and at least 3 flood-related stressors, respectively. The highest prevalence rate of current PTSD (30.8\%) occurred among victims with at least 3 flood-related stressors, followed by female victims $(24.3 \%)$. The bivariate associations between key covariates and current PTSD are presented in Table 2. Only flood-related stressors were significantly associated with the recovery from PTSD $(P<0.05)$.

The mean social support scores and their corresponding standard deviations on different study groups are shown in Table 3. Unmarried participants indicated 
Table 2 The distribution of current PTSD rate among different groups

\begin{tabular}{|c|c|c|c|c|c|c|}
\hline \multirow[b]{2}{*}{ Variable } & \multirow[b]{2}{*}{ Values } & \multicolumn{2}{|l|}{ Sample } & \multicolumn{2}{|l|}{ PTSD } & \multirow[b]{2}{*}{$P$ value $^{\mathrm{a}}$} \\
\hline & & Number & Percent (\%) & Number & Percent (\%) & \\
\hline \multirow[t]{3}{*}{ Gender } & & & & & & 0.321 \\
\hline & Female & 148 & 46.1 & 36 & 24.3 & \\
\hline & Male & 173 & 53.9 & 15 & 8.7 & \\
\hline \multirow[t]{3}{*}{ Age(year) } & & & & & & 0.093 \\
\hline & $29-59$ & 207 & 64.5 & 29 & 14.0 & \\
\hline & $\geq 60$ & 114 & 35.5 & 22 & 19.3 & \\
\hline \multirow[t]{3}{*}{ Marital status } & & & & & & 0.296 \\
\hline & Married & 295 & 91.9 & 45 & 15.3 & \\
\hline & Unmarried & 26 & 8.1 & 6 & 23.1 & \\
\hline \multirow[t]{3}{*}{ Educational level } & & & & & & 0.413 \\
\hline & sprimary school & 172 & 53.6 & 30 & 17.4 & \\
\hline & >primary school & 149 & 46.4 & 21 & 14.1 & \\
\hline \multirow[t]{3}{*}{ Flood-related stressors } & & & & & & $0.000^{* *}$ \\
\hline & $0-2$ & 243 & 75.7 & 27 & 11.1 & \\
\hline & $\geq 3$ & 78 & 24.3 & 24 & 30.8 & \\
\hline \multirow[t]{3}{*}{ Post-flood stressors } & & & & & & 0.138 \\
\hline & $0-2$ & 260 & 81.0 & 38 & 14.6 & \\
\hline & $\geq 3$ & 61 & 19.0 & 13 & 21.3 & \\
\hline
\end{tabular}

${ }^{\mathrm{a}}$ Two-tailed chi-square test

${ }^{* *} P<0.05$

lowest social support score $(28.54 \pm 6.72)$, lowest objective support score $(7.76 \pm 2.14)$, lowest subjective support score $(14.22 \pm 5.21)$ and lowest support utilization score $(6.58 \pm 1.84)$. Compared with individuals aged between 29 and 59, those whose age was 60 years or older showed lower support utilization score (6.71 for subjects 60 years or older versus 7.45 for subjects aged between 29 and $59, P<0.05)$ but higher subjective support score
(18.41 for subjects 60 years or older versus 16.48 for subjects aged between 29 and 59, $P<0.05$ ). Married participants had significantly higher scores than unmarried participants on objective support score (9.38 versus 7.76, $P<0.05)$, subjective support score (17.42 versus $14.22, P<$ 0.05 ) and social support score (34.04 versus $28.54, P<0.05$ ).

The bivariate relationship between social support and current PTSD are presented in Table 4 . The prevalence

Table 3 The distribution of social support score (Mean \pm SD) in different study groups

\begin{tabular}{|c|c|c|c|c|c|}
\hline \multirow[b]{2}{*}{ Variable } & \multirow[b]{2}{*}{ Value } & \multicolumn{4}{|c|}{ Social support score } \\
\hline & & Objective support & Subjective support & Support utilization & Total score \\
\hline \multicolumn{6}{|l|}{ Gender } \\
\hline & Female & $9.12 \pm 2.80$ & $16.98 \pm 6.38$ & $7.04 \pm 2.05$ & $33.12 \pm 8.02$ \\
\hline & Male & $9.36 \pm 2.89$ & $17.32 \pm 6.94$ & $7.32 \pm 2.37$ & $33.99 \pm 3.56$ \\
\hline \multicolumn{6}{|c|}{ Age(year) } \\
\hline & $29-59$ & $9.24 \pm 2.93$ & $16.48 \pm 6.05$ & $7.45 \pm 2.18$ & $33.17 \pm 8.17$ \\
\hline & $\geq 60$ & $9.26 \pm 2.70$ & $18.41 \pm 7.56^{*}$ & $6.71 \pm 2.24^{*}$ & $34.36 \pm 9.94$ \\
\hline \multicolumn{6}{|c|}{ Marital status } \\
\hline & Married & $9.38 \pm 2.86$ & $17.42 \pm 6.74$ & $7.24 \pm 2.54$ & $34.04 \pm 8.88$ \\
\hline & Unmarried & $7.76 \pm 2.14^{*}$ & $14.22 \pm 5.21^{*}$ & $6.58 \pm 1.84$ & $28.54 \pm 6.72^{*}$ \\
\hline \multicolumn{6}{|c|}{ Educational level } \\
\hline & sprimary school & $9.33 \pm 2.66$ & $17.82 \pm 7.23$ & $6.98 \pm 2.22$ & $34.12 \pm 9.45$ \\
\hline & $>$ primary school & $9.16 \pm 3.06$ & $16.40 \pm 5.91$ & $7.43 \pm 2.22$ & $32.98 \pm 8.08$ \\
\hline
\end{tabular}


Table 4 The relationship between current PTSD and social support

\begin{tabular}{|c|c|c|c|c|c|c|}
\hline & & Total sam & & PTSD & & \\
\hline & & Number & Percent (\%) & Number & Percent (\%) & $P$ value \\
\hline Objective support & & & & & & $0.024^{* *}$ \\
\hline & Low & 268 & 83.5 & 48 & 17.9 & \\
\hline & High & 53 & 16.5 & 3 & 5.7 & \\
\hline Subjective support & & & & & & $0.002^{* *}$ \\
\hline & Low & 242 & 75.4 & 47 & 19.4 & \\
\hline & High & 79 & 24.6 & 4 & 5.1 & \\
\hline Support utilization & & & & & & $0.004^{* *}$ \\
\hline & Low & 256 & 79.8 & 48 & 18.8 & \\
\hline & High & 65 & 20.2 & 3 & 4.6 & \\
\hline Social support & & & & & & $0.004^{* *}$ \\
\hline & Low & 266 & 82.9 & 49 & 18.4 & \\
\hline & High & 55 & 17.1 & 2 & 3.6 & \\
\hline
\end{tabular}

${ }^{\mathrm{a}}$ Two-tailed chi-square test

${ }^{* *} P<0.05$

rate of current PTSD was significantly higher among individuals with low social support than among those with high social support $(18.4 \%$ versus $3.6 \%, P<0.05)$. The same relationship between current PTSD and social support was observed in all 3 dimensions of social support.

The results of logistic regression analyses are shown in Table 5. Each logistic regression analysis included only one social support variable to avoid multicollinearity among the different social support variables. Four multivariate logistic regression analyses were conducted with current PTSD as the dependent variable. The latent variable of social support and its 3 categories were independent variables and key covariates stated above were control variables. The results showed that the adjusted OR for current PTSD was 0.202 (95 \% CI: 0.047-0.878) for high social support, 0.336 (95\% CI: 0.098-1.157) for high objective support; 0.236 (95 \% CI: 0.080-0.694) for high subjective support and 0.245 (95 \% CI: 0.071-0.844) for high support utilization.

\section{Discussion}

PTSD is a common psychological disorder in disasteraffected populations and has been widely used to assess the psychological impact of natural disasters. Although many studies about the effect of social support on trauma victims have been reported, to our knowledge this is the first study to explore the association between social support and the recovery from prior PTSD after flood.

This 13-to-14-year follow-up study showed that the prevalence rate of current PTSD among subjects with prior PTSD was $15.89 \%$. This rate is lower than both the one calculated from the police responders convalescent $(53 \%)$ after the terrorist attack of September 11, 2001 [5] and the one calculated from the severe acute respiratory syndrome (SARS) patients (34.29\%) [30]. It has been well established that different types of traumatic events and different levels of the intensity of disasters result in different prevalence rates of current PTSD [31]. In addition, follow-up time may also affect the prevalence rate of current PTSD in that the longer follow-up time may give the victims sufficient time to recover from the trauma and therefore lower the prevalence rate of current PTSD. It is believed that few studies about PTSD have followed up a target population after the space of time longer than this follow-up study.

Table 5 The relationship between social support and current PTSD among participants by logistic regression analyses

\begin{tabular}{lcccc}
\hline Characteristic & ${\text { Crude } \mathrm{OR}^{\mathrm{a}}}$ & $95 \% \mathrm{Cl}$ & Adjusted OR $^{\mathrm{b}}$ & $95 \% \mathrm{Cl}$ \\
\hline High objective support & 0.275 & $0.082-0.919$ & 0.336 & $0.098-1.157$ \\
High subjective support & 0.221 & $0.077-0.635$ & 0.236 & $0.080-0.694$ \\
High support utilization & 0.210 & $0.063-0.696$ & 0.245 & $0.071-0.844$ \\
High social support & 0.167 & $0.039-0.709$ & 0.202 & $0.047-0.878$
\end{tabular}

$95 \%$ Cl $95 \%$ confidence interval, OR odds ratio

${ }^{a}$ Crude OR was calculated using bivariate logistic regression analyses

${ }^{\mathrm{b}}$ Adjusted OR was calculated using multivariate logistic regression analyses adjusted for age, sex, education, marital status, flood-related stressors, post-flood stressors and coping style 
In this study, it was also found that individuals with less flood-related stressors were more prone to recover from prior PTSD than those with more flood-related stressors. This was consistent with many reported studies that aimed at finding risk factors of PTSD [5, 32, 33]. Trauma-related stressors are not only related to the incidence of PTSD but also associated with the recovery from prior PTSD. Victims experiencing more floodrelated stressors may need relatively more time to recover from the pain that disasters inflicted on their bodies and minds.

It is widely understood that social support is a network of family, friends, colleagues, neighbors or anyone a person can turn to when faced with some trouble. This study not only evaluated social support in that sense but also considered comprehensive social support from the government, local communities and nongovernmental organizations. It was found that social support was closely related to some demographic characteristics. There was a higher level of subjective support, objective support and social support in married participants than in unmarried participants. Overall, family members seem to be the first choice to provide any kind of social support and the support from one's spouse even plays an irreplaceable role in one's perceived social support [34]. Also, there was a higher level of subjective support in the elderly than in the young. However, the young showed a higher level of support utilization than the elderly. These observations could possibly result from the fact that the elderly have much wider social interactions than the young by virtue of their age, but it is also because of their age, they have not so many ways to utilize social support as the young. With the development of the social network connections, young people can make use of such tools to obtain social support, but it's relatively hard for the elderly to take advantage of these social network connections.

Social support refers to the function and quality of social relationships and may affect the way one copes with stress. According to some researches, social support can act as a buffer and then lessen or even prevent the stress from occurring [35]. Notably, social support and good relationships with family members can increase quality of life [36]. A number of studies had proved that social support was associated with the onset of PTSD [14, 37-40], but it was unclear whether social support may influence the recovery from prior PTSD or not. The results of this follow-up study revealed that social support was positively correlated with the recovery from PTSD. Strong social support can not only protect individuals from suffering from psychological disorders, but also facilitate the psychological recovery from disasters. Therefore, social support may have a long-term influence on alleviating the psychological effect of flood.
As for the 3 dimensions of social support, subjective support is a kind of social support experienced or felt by oneself; objective support is a kind of visible or actual social support; and support utilization refers to the utilizing degree to which the available social support is used. In this study, it was found that social support, subjective support and support utilization were significantly associated with current PTSD. After adjusting for the potential confounding variables by multivariate logistic regression analyses, the results did not change. Objective support was not significantly associated with current PTSD after adjusting for the potential confounding variables. Unlike the objective support, subjective support is more about the feeling of being supported. Subjective assessment of received social support has been reported to be a more powerful predictor of subsequent improvement in psychological disorders than objective measures of social support. This is the case because one's psychological perception of reality could affect individual's behavior and development $[41,42]$. Although significant correlation between objective support and the recovery from prior PTSD was not found in this study, it was worth putting on record that objective support was also irreplaceable. Components of objective support, such as economic assistance and psychological intervention, often serve as the foundation for subjective support and support utilization. The reason for no significant relationship between objective support and the recovery from prior PTSD could be due to an even distribution of objective support to flood victims by local government or communities.

Certain limitations of this study should be acknowledged. Firstly, the fluctuations of the recovery from prior PTSD and the social support level over time were uncertain because the follow-up of the target population was done only once. Secondly, the causal effect of social support and the recovery from prior PTSD were not clear. Thirdly, the diagnosis of current PTSD was made according to the DSM-IV criteria by using a self-reporting scale rather than a structured clinical interview. Selfreporting scales may not always provide accurate representation of PTSD symptomatology. However, the PCL-C used in this study was well validated and it was also used to identify PTSD in the first investigation. Finally, all participants enrolled in this study were Chinese of Han ethnicity. Hence, the results may not be applicable to other populations.

\section{Conclusion}

This follow-up study explored the association between social support and the recovery from prior PTSD among the 1998 Dongting Lake flood victims. The study found that the prevalence rate of current PTSD among individuals with prior PTSD was $15.89 \%$ and social support 
was significantly associated with the recovery from prior PTSD. Victims of Dongting Lake flood in 1998, who were diagnosed as having PTSD in 2000, and had a high level of social support, subjective support and support utilization, were more prone to recover from prior PTSD.

\section{Abbreviations \\ 95 \% Cl: 95 \% confidence interval; DSM: diagnostic and Statistical Manual; OR: odds ratio; PCL-C: PTSD Checklist-Civilian version.; PTSD: post-traumatic stress disorder; SSRS: Chinese version of Social Support Rating Scale.}

\section{Competing interests}

The authors declare that they have no competing interests.

\section{Authors' contributions}

WD participated in the field survey of the study and drafted the manuscript. $L C, Z L$ and $Y L$ participated in the field survey. AL contributed to the study design. HT contributed to the data collection. JW and AK helped to edit the language. All authors participated in critical revision of the manuscript drafts and approved the final version.

\section{Acknowledgments}

We are grateful to all participants, investigators, officials and community workers of the local government. This study was supported by the Specialized Research Fund for the Doctoral Program of Higher Education (20130162110054)

\section{Author details}

'Department of Epidemiology and Health Statistics, School of Public Health, Central South University, Hunan, China. ${ }^{2}$ Zhuhai Center for Disease Control and Prevention, Guangdong, China. ${ }^{3}$ Department of Pediatrics, University of Pittsburgh School of Medicine, Pittsburgh, USA.

Received: 11 November 2015 Accepted: 16 February 2016 Published online: 29 February 2016

\section{References}

1. Breisinger C, Ecker O, Thiele R, Wiebelt M. Effects of the 2008 flood on economic performance and food security in Yemen: a simulation analysis. Disasters. 2015. doi:10.1111/disa.12147.

2. Carmassi C, Akiskal HS, Yong SS, Stratta P, Calderani E, Massimetti E, et al. Posttraumatic stress disorder in DSM-5: estimates of prevalence and criteria comparison versus DSM-IV-TR in a non-clinical sample of earthquake survivors. Journal of Affective Disorders. 2013;151(3):843-8. doi:10.1016/j.jad.2013.07.020.

3. Hidalgo RB, Davidson JR. Posttraumatic stress disorder: epidemiology and health-related considerations. The Journal of Clinical Psychiatry. 2000;61 Suppl 7:5-13.

4. Perkonigg A, Pfister $\mathrm{H}$, Stein MB, Hofler M, Lieb R, Maercker A, et al. Longitudinal course of posttraumatic stress disorder and posttraumatic stress disorder symptoms in a community sample of adolescents and young adults. The American Journal of Psychiatry. 2005;162(7):1320-7. doi:10.1176/appi.ajp.162.7.1320.

5. Cone JE, Li J, Kornblith E, Gocheva V, Stellman SD, Shaikh A, et al. Chronic probable ptsd in police responders in the world trade center health registry ten to eleven years after 9/11. American Journal of Industrial Medicine. 2015;58(5):483-93. doi:10.1002/ajim.22446.

6. Celebi Oncu E, Wise AM. The effects of the 1999 Turkish earthquake on young children: analyzing traumatized children's completion of short stories. Child Development. 2010:81(4):1161-75. doi:10.1111/j.1467-8624.2010.01460.x.

7. Iwadare Y, Usami M, Suzuki Y, Ushijima H, Tanaka T, Watanabe K, et al. Posttraumatic symptoms in elementary and junior high school children after the 2011 Japan earthquake and tsunami: symptom severity and recovery vary by age and sex. The Journal of Pediatrics. 2014;164(4):917-21. e1. doi:10.1016/j.jpeds.2013.11.061.

8. Ren ZJ, Deng H, Hsu LK. PTSD in a one year old girl after the Wenchuan earthquake in Sichuan, China. Psychiatry. 2011;74(1):87-92. doi:10.1521/psyc. 2011.74.1.87.

9. Arcaya MC, Lowe SR, Rhodes JE, Waters MC, Subramanian SV. Association of PTSD symptoms with asthma attacks among hurricane Katrina survivors. Journal of Traumatic Stress. 2014;27(6):725-9. doi:10.1002/jts.21976.
10. McCanlies EC, Mnatsakanova A, Andrew ME, Burchfiel CM, Violanti JM. Positive psychological factors are associated with lower PTSD symptoms among police officers: post Hurricane Katrina. Stress and Health. 2014;30(5):405-15. doi:10.1002/smi.2615.

11. McLaughlin KA, Berglund P, Gruber MJ, Kessler RC, Sampson NA, Zaslavsky AM. Recovery from PTSD following Hurricane Katrina. Depression and Anxiety. 2011;28(6):439-46. doi:10.1002/da.20790.

12. Azad Marzabadi E, Hashemi Zadeh SM. The Effectiveness of Mindfulness Training in Improving the Quality of Life of the War Victims with Post Traumatic stress disorder (PTSD). Iranian Journal of Psychiatry. 2014;9(4):228-36.

13. Ferrajao PC, Oliveira RA. The Effects of Combat Exposure, Abusive Violence, and Sense of Coherence on PTSD and Depression in Portuguese Colonial War Veterans. Psychological Trauma. 2016;8(1):1-8. doi:10.1037/tra0000043.

14. Gil S, Weinberg M, Or-Chen K, Harel H. Risk factors for DSM 5 PTSD symptoms in Israeli civilians during the Gaza war. Brain and Behavior. 2015;5(4):e00316. doi:10.1002/brb3.316.

15. O'Donnell K. Help for Heroes: PTSD, Warrior Recovery, and the Liturgy. Journal of Religion and Health. 2015;54(6):2389-97. doi:10.1007/s10943-015-0034-5.

16. Shaikh al arab A, Guedon-Moreau L, Ducrocq F, Molenda S, Duhem S, Salleron $J$, et al. Temporal analysis of heart rate variability as a predictor of post traumatic stress disorder in road traffic accidents survivors. Journal of Psychiatric Research. 2012;46(6):790-6. doi:10.1016/j.jpsychires.2012.02.006.

17. Chossegros L, Hours M, Charnay P, Bernard M, Fort E, Boisson D, et al. Predictive factors of chronic post-traumatic stress disorder 6 months after a road traffic accident. Accident; Analysis and Prevention. 2011:43(1):471-7. doi:10.1016/j.aap.2010.10.004

18. Liu A, Tan H, Zhou J, Li S, Yang T, Sun Z, et al. Brief screening instrument of posttraumatic stress disorder for children and adolescents 7-15 years of age. Child Psychiatry and Human Development. 2007;38(3):195-202. doi:10.1007/s10578-007-0056-7.

19. Liu A, Tan H, Zhou J, Li S, Yang T, Tang X, et al. A short DSM-IV screening scale to detect posttraumatic stress disorder after a natural disaster in a Chinese population. Psychiatry Research. 2008;159(3):376-81. doi:10.1016/j. psychres.2007.08.015.

20. Liu A, Tan H, Zhou J, Li S, Yang T, Wang J, et al. An epidemiologic study of posttraumatic stress disorder in flood victims in Hunan China. Canadian Journal of Psychiatry Revue canadienne de psychiatrie. 2006;51 (6):350-4.

21. Demirtepe-Saygili D, Bozo O. Perceived social support as a moderator of the relationship between caregiver well-being indicators and psychological symptoms. Journal of Health Psychology. 2011;16(7):1091-100. doi:10.1177/ 1359105311399486.

22. Trickey D, Siddaway AP, Meiser-Stedman R, Serpell L, Field AP. A meta-analysis of risk factors for post-traumatic stress disorder in children and adolescents. Clinical Psychology Review. 2012;32(2):122-38. doi:10.1016/j.cpr.2011.12.001.

23. Feng S, Tan H, Benjamin A, Wen S, Liu A, Zhou J, et al. Social support and posttraumatic stress disorder among flood victims in Hunan, China. Ann Epidemiol. 2007:17(10):827-33. doi:10.1016/j.annepidem.2007.04.002.

24. Huang P, Tan H, Liu A, Feng S, Chen M. Prediction of posttraumatic stress disorder among adults in flood district. BMC Public Health. 2010;10:207. doi:10.1186/1471-2458-10-207.

25. Xiao $\mathrm{S}$. The theoretical basis and research applications of the Social Support Scale. Journal of Clinical Psychiatry. 1994;4(02):98-100.

26. Xu J, Ou L. Resilience and quality of life among Wenchuan earthquake survivors: the mediating role of social support. Public Health. 2014;128(5): 430-7. doi:10.1016/.jpuhe.2014.03.002.

27. Liu J, Li F, Lian Y. Investigation of reliability and validity of the social support scale. Journal of Xinjiang Medical University. 2008;31(1):1-3.

28. Ruggiero KJ, Del Ben K, Scotti JR, Rabalais AE. Psychometric properties of the PTSD Checklist-Civilian Version. Journal of Traumatic Stress. 2003;16(5): 495-502. doi:10.1023/a:1025714729117.

29. Blanchard EB, Jones-Alexander J, Buckley TC, Forneris CA. Psychometric properties of the PTSD Checklist (PCL). Behaviour Research and Therapy. 1996;34(8):669-73.

30. Hong X, Currier GW, Zhao X, Jiang Y, Zhou W, Wei J. Posttraumatic stress disorder in convalescent severe acute respiratory syndrome patients: a 4year follow-up study. General Hospital Psychiatry. 2009;31(6):546-54. doi:10.1016/j.genhosppsych.2009.06.008.

31. Xue C, Ge Y, Tang B, Liu Y, Kang P, Wang M, et al. A meta-analysis of risk factors for combat-related PTSD among military personnel and veterans. PloS One. 2015;10(3):e0120270. doi:10.1371/journal.pone.0120270. 
32. Tiihonen Moller A, Backstrom T, Sondergaard HP, Helstrom L. Identifying risk factors for PTSD in women seeking medical help after rape. PloS One. 2014;9(10):e111136. doi:10.1371/journal.pone.0111136.

33. DiGrande L, Perrin MA, Thorpe LE, Thalji L, Murphy J, Wu D, et al. Posttraumatic stress symptoms, PTSD, and risk factors among lower Manhattan residents 2-3 years after the September 11, 2001 terrorist attacks. Journal of Traumatic Stress. 2008;21(3):264-73. doi:10.1002/jts.20345.

34. Tilburgs B, Nijkamp MD, Bakker EC, van der Hoeven H. The influence of social support on patients' quality of life after an intensive care unit discharge: A cross-sectional survey. Intensive \& critical care nursing: the official journal of the British Association of Critical Care Nurses. 2015;31(6): 336-42. doi:10.1016/j.iccn.2015.07.002.

35. Huh J, Liu LS, Neogi T, Inkpen K, Pratt W. Health Vlogs as Social Support for Chronic Illness Management. ACM transactions on computer-human interaction : a publication of the Association for Computing Machinery. 2014;21(4). doi:10.1145/2630067

36. Tempski P, Bellodi PL, Paro HB, Enns SC, Martins MA, Schraiber LB. What do medical students think about their quality of life? A qualitative study. BMC Medical Education. 2012;12:106. doi:10.1186/1472-6920-12-106.

37. Wright BK, Kelsall HL, Sim MR, Clarke DM, Creamer MC. Support mechanisms and vulnerabilities in relation to PTSD in veterans of the Gulf War, Iraq War, and Afghanistan deployments: a systematic review. Journal of Traumatic Stress. 2013;26(3):310-8. doi:10.1002/jts.21809.

38. Panagioti M, Gooding PA, Taylor PJ, Tarrier N. Perceived social support buffers the impact of PTSD symptoms on suicidal behavior: implications into suicide resilience research. Comprehensive Psychiatry. 2014;55(1): 104-12. doi:10.1016/j.comppsych.2013.06.004.

39. Klaric M, Franciskovic T, Klaric B, Kresic M, Grkovic J, Lisica ID, et al. Social support and PTSD symptoms in war-traumatized women in Bosnia and Herzegovina. Psychiatria Danubina. 2008;20(4):466-73.

40. Feder A, Ahmad S, Lee EJ, Morgan JE, Singh R, Smith BW, et al. Coping and PTSD symptoms in Pakistani earthquake survivors: purpose in life, religious coping and social support. Journal of Affective Disorders. 2013;147(1-3):156-63. doi:10.1016/j.jad.2012.10.027.

41. Ren J, Jiang X, Yao J, Li X, Liu X, Pang M, et al. Depression, Social Support, and Coping Styles among Pregnant Women after the Lushan Earthquake in Ya'an, China. PloS One. 2015;10(8):e0135809. doi:10.1371/journal.pone. 0135809.

42. Ma L, Li Y, Wang J, Zhu H, Yang W, Cao R, et al. Quality of Life Is Related to Social Support in Elderly Osteoporosis Patients in a Chinese Population. PloS One. 2015;10(6):e0127849. doi:10.1371/journal.pone.0127849.

\section{Submit your next manuscript to BioMed Central and we will help you at every step:}

- We accept pre-submission inquiries

- Our selector tool helps you to find the most relevant journal

- We provide round the clock customer support

- Convenient online submission

- Thorough peer review

- Inclusion in PubMed and all major indexing services

- Maximum visibility for your research

Submit your manuscript at www.biomedcentral.com/submit

) Biomed Central 